\title{
О.А. Ястребов
}

\section{РЕЦЕНЗИЯ НА МОНОГРАФИЮ: БЕГИШЕВ И.Р., ХИСАМОВА З.И. ИСКУССТВЕННЫЙ ИНТЕЛЛЕКТ И УГОЛОВНЫЙ ЗАКОН. М.: ПРОСПЕКТ, 2021. 11,5 авТ. Л.}

\begin{abstract}
Дается краткая рецензия на монографию «Искусственный интеллект и уголовный закон», подготовленную старшим научным сотрудником Казанского инновационного университета имени В.Г. Тимирясова (ИЭУП), кандидатом юридических наук, заслуженным юристом Республики Татарстан И.Р. Бегишевым и начальником отделения планирования и координации научной деятельности научно-исследовательского отдела Краснодарского университета Министерства внутренних дел Российской Федерации, кандидатом юридических наук 3.И. Хисамовой.
\end{abstract}

Ключевые слова: искусственный интеллект, криминология, ответственность, правосубъектность, робот, робототехника, уголовное право, циифровые технологии, электронное лицо, автономность.

Высокие темпы развития цифровых технологий и активное расширение сфер их применения кардинальным образом изменили устоявшиеся общественные взаимоотношения. В частности, возможности искусственного интеллекта растут беспрецедентными темпами. Технология имеет много полезных применений, начиная от машинного перевода и заканчивая анализом медицинских изображений. Несомненно, такие беспрецедентные возможности не остаются в стороне от внимания мировой общественности. Более 80 стран мира сегодня ведут активные разработки в области прикладного применения технологии искусственного интеллекта. Особая роль в этом процессе принадлежит технологическим корпорациям, чей энтузиазм, помноженный на желание извлечь прибыль благодаря инновациям, приближает нас к моменту, когда технология искусственного интеллекта станет полностью автономной и независимой от человека. Между тем, не заглядывая в будущее, уже сегодня можно говорить о том, что технологические инновации, ставшие основным драйвером глобального экономического развития, являют собой также и источник новых вызовов и рисков. Однако мировое сообщество только начинает осознавать реальные и потенциальные нюансы влияния полностью автоматизированных систем на жизненно важные области социальных отношений, на рост связанных с данной тенденцией этических, социальных и правовых проблем [1].

Вопросы использования новых технологий часто выходят за рамки устоявшихся этических норм и требуют их пересмотра не только с точки зрения изменения общественных ценностей, но и развития законодательства.

В этом аспекте работы, посвященные осмыслению правовых аспектов применения цифровых технологий, представляются как никогда актуальными и значимыми. В свою очередь, рецензируемая монография [2] представляет собой как раз исследование, посвященное изучению корреляционных связей между искусственным интеллектом и отдельной отраслью права - уголовной.

Надо отметить, что если работы, посвященные в целом правовому регулированию искусственного интел- лекта, уже известны современной науке, то непосредственно посвященных изучению точек соприкосновения искусственного интеллекта и уголовного закона специальных монографических исследований еще не было.

С учетом изложенного имеются основания утверждать, что избранная авторами тема монографии является актуальной и своевременной для исследования. Ее актуальность обусловливается также тем, что вопросы ответственности, в том числе уголовной, будут возникать все чаще в связи с возрастающей автономностью систем с искусственным интеллектом.

Надо сказать, что работа представляет собой логический итог завершения цикла публикаций авторов, посвященных проблемам правового регулирования искусственного интеллекта [3-14].

Интересна как с теоретической, так и практической точек зрения часть исследования, посвященная рассмотрению проблем разграничения понятийного аппарата в области робототехники и искусственного интеллекта. Заслуживает поддержки тезис авторов о том, что, несмотря на имеющиеся пересечения и взаимодополнения упомянутых технологий, все же нельзя однозначно утверждать, что робототехника и искусственный интеллект - это одно и то же. К сожалению, терминологическая путаница наблюдается сегодня как в юридической науке, так и в иных сферах. Между тем такое явление, на мой взгляд, обусловлено определенной незрелостью правового оформления рассматриваемых отношений.

Положительной оценки заслуживает часть исследования, посвященная проблемам соотношения уголовноправовых норм и деликтов, совершаемых с участием робототехники и искусственного интеллекта. Выводы и рекомендации авторов в указанном аспекте, несомненно, обладают определённой практической значимостью и будут положительно восприняты правоприменителем.

В рецензируемой работе последовательно раскрываются основные аспекты темы. Начав от истории становления и развития науки об искусственном интеллекте, авторы знакомят читателя с теоретическими подходами к толкованию понятия «искусственный ин- 
теллект», проблемами разграничения понятийного аппарата, задаются осмыслением искусственного интеллекта и робота как правовых категорий, обращаясь при этом не только к отечественным источникам, но и к западной правовой литературе, а также к актам международных организаций, посвященных правовому регулированию искусственного интеллекта и робототехники. Надо сказать, что работа основывается на достаточно прочном теоретическом фундаменте. В монографии приводится подробный анализ как широко известных в науке мнений по исследуемой теме, так и частные теории, что, несомненно, выставляет работу в выгодном свете.

Авторы высказывают также весьма обоснованно свою позицию относительно возможности наделения систем с искусственным интеллектом статусом «электронного лица», широко обсуждаемой как на мировой арене, так и в науке.

Во второй главе монографии рассматриваются основные подходы к правовому регулированию искусственного интеллекта в мире. При этом, учитывая заглавие монографии, основное внимание сосредоточено на криминальных угрозах и инициативах по их минимизации.

Стоит отметить, что методологически верным представляется и рассмотрение вопросов международноправового регулирования с позиций саморегулирования отрасли, регулирования в рамках отдельно взятых стран и на глобальном уровне.

В этой части работы авторами рассматривается круг проблем, выходящих за пределы заявленной темы, но между тем это нельзя назвать недостатком в чистом виде, а скорее следует признать проявлением научного интереса к междисциплинарным проблемам.

В третьей главе исследования, посвященной уголовно-правовым и криминологическим аспектам применения искусственного интеллекта и робототехники, достаточно много внимания уделяется этическим и криминологическим рискам применения искусственного интеллекта и робототехники. Это вполне оправданно, так как этические риски, возможные при использовании ИИ-технологий, весьма чувствительны. К примеру, использование роботов и систем с искусственным интеллектом в военных целях ставит одновременно несколько этических вопросов: в каких ситуациях прекращать огонь, в какой обстановке стремиться све- сти к минимуму количество жертв. На все эти вопросы мировое сообщество только начинает искать ответы. В свою очередь, использование искусственного интеллекта, причинившего вред общественным отношениям, также весьма неоднозначное явление. Открытым остается вопрос о том, кто непосредственно будет нести ответственность за реализованное в жизнь неправильное решение, предложенное «искусственным интеллектом» либо решение, принятое автономным искусственным интеллектом во имя «всеобщего блага», но идущее вразрез общечеловеческой морали. Такого рода правовая неопределенность уже сейчас создает в обществе серьезные проблемы, которые будут нарастать в геометрической прогрессии. И в рецензируемой работе есть весьма интересные предложения по их разрешению. Например, авторы моделируют варианты «привлечения искусственного интеллекта к ответственности» при наделении искусственного интеллекта правосубъектностью.

В целом подход, при котором в научном исследовании не только выносятся на обсуждение научной общественности имеющиеся в рамках изучаемой темы проблемы, но и предлагаются модели их разрешения, представляется наиболее перспективным для современной науки и практики.

Резюмируя вышеизложенное, следует отметить, что работа состоялась и она, бесспорно, своевременна. Системы с искусственным интеллектом становятся всё более автономными в смысле сложности задач, которые они могут выполнять, их потенциального влияния на мир и уменьшающейся способности человекасоздателя понимать, предсказывать и контролировать их деятельность. Все это ставит перед нами вопросы: в долгосрочной перспективе - о создании отдельного регулирования робототехники и систем с искусственным интеллектом при достижении технологической сингулярности; а в краткосрочной - создании правовой базы, которая обеспечит предсказуемость технологий и их безопасность для интересов человечества.

Полагаю, рецензируемая научно-исследовательская работа соответствует требованиям, предъявляемым к такому виду работ, выполнена на достаточно высоком научном уровне и будет полезна для широкого круга читателей, интересующихся вопросами правового регулирования искусственного интеллекта и робототехники.

\section{ЛИТЕРАТУРА}

1. Ястребов О.А. Искусственный интеллект в правовом пространстве // Вестник РУДН. Серия: Юридические науки. 2018. Т. 22, № 3. 315-328.

2. Бегишев И.Р., Хисамова З.И. Искусственный интеллект и уголовный закон. М. : Проспект, 2021.

3. Бегишев И.Р., Хисамова З.И. Искусственный интеллект и робототехника: глоссарий понятий. М. : Проспект, 2021.

4. Бегишев И.Р., Хисамова З.И. Криминологические риски применения искусственного интеллекта // Всероссийский криминологический журнал. 2018. Т. 12, № 6. С. 767-775.

5. Бегишев И.Р., Хисамова З.И. Искусственный интеллект и робототехника: теоретико-правовые проблемы разграничения понятийного аппарата // Вестник Удмуртского университета. Серия: Экономика и право. 2020. Т. 30, № 5. С. $710-718$.

6. Хисамова З.И., Бегишев И.Р. Уголовная ответственность и искусственный интеллект: теоретические и прикладные аспекты // Всероссийский криминологический журнал. 2019. Т. 13, № 4. С. 564-574.

7. Хисамова З.И., Бегшщев И.Р. История становления и теоретико-правовые подходы к толкованию понятия «искусственный интеллект» // Алтайский юридический журнал. 2020. № 3 (31). С. 31-38. 
8. Хисамова З.И., Бегишев И.Р. Сущность искусственного интеллекта и проблема определения правосубъектности // Вестник Московского государственного областного университета. Серия: Юриспруденция. 2020. № 2. С. 96-106.

9. Хисамова 3.И., Бегишев И.Р. Правовое регулирование искусственного интеллекта // Baikal Research Journal. 2019. Т. 10 , № 2.

10. Khisamova Z.I., Begishev I.R., Sidorenko E.L. Artificial Intelligence and Problems of Ensuring Cyber Security // International Journal of Cyber Criminology. 2019. Vol. 13, No 2. P. 564-577.

11. Khisamova Z.I., Begishev I.R., Gaifutdinov R.R. On Methods to Legal Regulation of Artificial Intelligence in the World // International Journal of Innovative Technology and Exploring Engineering. 2019. Vol. 9, No 1. P. 5159-5162.

12. Bikeev I.I., Kabanov P.A., Begishev I.R., Khisamova Z.I. Criminological Risks and Legal Aspects of Artificial Intelligence Implementation // In Proceedings of the International Conference on Artificial Intelligence, Information Processing and Cloud Computing (AIIPCC '19). New York: Association for Computing Machinery, 2019. Art. 20. P. 1-7.

13. Bokovnya A.Yu., Begishev I.R., Khisamova Z.I., Bikeev I.I., Sidorenko E.L., Bersei D.D. Pressing Issues of Unlawful Application of Artificial Intelligence // International Journal of Criminology and Sociology. 2020. Vol. 9. P. 1-4.

Book Review: Begishev, I.R. \& Khisamova, Z.I. (2021) Iskusstvennyy Intellekt $i$ Ugolovnyy Zakon [Artificial Intelligence and Criminal Law]. Moscow: Prospekt

Ugolovnaya yustitsiya - Russian Journal of Criminal Law, 2020, no. 16, pp. 130-132. DOI: 10.17223/23088451/16/25

Oleg A. Yastrebov, Peoples' Friendship University of Russia (Moscow, Russian Federation). E-mail: rudnoleg@gmail.com

Keywords: artificial intelligence, criminology, responsibility, legal personality, robot, robotics, criminal law, digital technologies, electronic entity, autonomy.

The article provides a brief review of the monograph Artificial Intelligence and Criminal Law. The book examines the criminal law and criminology aspects of using artificial intelligence for criminal purposes. Special attention is paid to the regulation of the legal personality of artificial intelligence as a fundamental issue in delineation of responsibility. The book presents the results of a comprehensive theoretical and applied analysis of the main contemporary doctrines on the regulation of artificial intelligence and robotics, as well as of a comparative legal analysis of international legislation aimed at minimizing the criminological risks associated with the use of artificial intelligence.

\section{References}

1. Yastrebov, O.A. (2018) Artificial intelligence in the legal space. Vestnik RUDN. Seriya: Yuridicheskie nauki-RUDN Journal of Law. 22 (3). pp. 315-328. (In Russian). DOI: 10.22363/2313-2337-2018-22-3-315-328

2. Begishev, I.R., \& Khisamova, Z.I. (2021) Iskusstvennyy intellekt i ugolovnyy zakon [Artificial Intelligence and Criminal Law]. Moscow: Izd-vo Prospekt. (in print).

3. Begishev, I.R. \& Khisamova, Z.I. (2021) Iskusstvennyy intellekt i robototekhnika: glossariy ponyatiy [Artificial Intelligence and Robotics: A Glossary of Concepts]. Moscow: Izd-vo Prospekt. (in print).

4. Begishev, I.R. \& Khisamova, Z.I. (2018) Criminological Risks of Using Artificial Intelligence. Vserossiyskiy kriminologicheskiy zhurnal - Russian Journal of Criminology. 12 (6). pp. 767-775. (In Russian). DOI: 10.17150/2500-4255.2018.12(6).767-775

5. Begishev, I.R. \& Khisamova, Z.I. (2020) Artificial Intelligence and Robotics: Theoretical and Legal Problems of Differentiation of the Conceptual Apparatus. Vestnik Udmurtskogo universiteta. Seriya Ekonomika i pravo - Bulletin of Udmurt University. Series Economics and Law. 30 (5). pp. 710-718. (In Russian).

6. Khisamova, Z.I. \& Begishev, I.R. (2019) Criminal Liability and Artificial Intelligence: Theoretical and Applied Aspects. Vserossiyskiy kriminologicheskiy zhurnal - Russian Journal of Criminology. 13 (4). pp. 564-574. (In Russian). DOI: 10.17150/25004255.2019.13(4).564-574

7. Khisamova, Z.I. \& Begishev, I.R. (2020) The History of the Formation of Theoretical and Legal Approaches to the Interpretation of the Concept of “Artificial Intelligence”. Altayskiy yuridicheskiy zhurnal - Altai Law Journal. 3 (31). pp. 31-38. (In Russian).

8. Khisamova, Z.I. \& Begishev, I.R. (2020) The Nature of Artificial Intelligence and the Problem of Legal Personality Determination. Vestnik Moskovskogo gosudarstvennogo oblastnogo universiteta. Seriya: Yurisprudentsiya - Bulletin of the Moscow Region State University. Series: Jurisprudence. 2. pp. 96-106. (In Russian). DOI: 10.18384/2310-6794-2020-2-96-106

9. Khisamova, Z.I. \& Begishev, I.R. (2019) Legal Regulation of Artificial Intelligence. Baikal Research Journal. 10 (2). (In Russian).

10. Khisamova, Z.I., Begishev, I.R. \& Sidorenko, E.L. (2019) Artificial Intelligence and Problems of Ensuring Cyber Security. International Journal of Cyber Criminology.13 (2). pp. 564-577.

11. Khisamova, Z.I., Begishev, I.R. \& Gaifutdinov, R.R. (2019) On Methods to Legal Regulation of Artificial Intelligence in the World. International Journal of Innovative Technology and Exploring Engineering. 9 (1). pp. 5159-5162.

12. Bikeev, I.I. et al. (2019) Criminological Risks and Legal Aspects of Artificial Intelligence Implementation. Proceedings of the International Conference on Artificial Intelligence, Information Processing and Cloud Computing (AIIPCC'19). New York: Association for Computing Machinery. Art. 20. pp. 1-7.

13. Bokovnya, A.Yu. et al. (2020) Pressing Issues of Unlawful Application of Artificial Intelligence. International Journal of Criminology and Sociology. 9. pp. 1-4. 